\title{
Urban Planning with a GIS at School
}

\author{
Robert PLÖTZ, Klaus PINZEK and Friedrich BARNIKEL \\ Städtisches Adolf-Weber-Gymnasium München / Germany·friedrich.barnikel@awg.musin.de
}

This contribution was double-blind reviewed as extended abstract.

\begin{abstract}
Several school projects have already proven the value of working with a GIS in the classroom. As a consequence, curricula in several European countries have included GI in education. But few groups/classes so far have used a professional GIS when creating maps. This project describes the results of a workshop that has been running for one-and-a-half years at an upper secondary school ("Gymnasium") in Munich, Germany. Neither the three teachers leading the workshop nor the students attending the workshop had any active knowledge about GIS when starting the project. At the end of the workshop period the group had devised a complete digital plan for urban development (calculated for ten thousand inhabitants) in an undeveloped area in the north of Munich, using ArcGIS.
\end{abstract}

\section{Introduction}

A few years ago, Bavarian high schools ("Gymnasien") shortened the way to the university-entrance diploma ("Abitur") from nine to eight years, thus adopting a system, which has been implemented all over Germany recently. Part of the new concept is a project seminar for occupational orientation for all candidates during their last two years at school. Half of the time in this seminar is dedicated to career training, the other half for the development of a (by and large self-guided) project. The project "urban planning" within the seminar was led by three teachers at the municipal Adolf-Weber-Gymnasium in Munich, Germany. One of them is a teacher for Informatics, Mathematics and Physics, one is the IT administrator of the school, Head of Mathematics and a teacher for Physics, and the third is the Educational Coordinator for Geography for the municipal secondary schools in Munich. None of them had any knowledge about the use of a GIS when starting the project. One was taught in a Comenius teacher training programme in Ireland in 2012, organised by the European Association of Geographers (cf. www.eurogeography.eu) and the two others acquired their knowledge the same way as the students, with the help of a training manual for ArcGIS, written by an ESRI-team to be used with a school atlas (BREYER, JOACHIM, SCHOBER \& TSCHIRNER (2010). In both cases the version of the GIS used was ArcGIS 9.3.1, which was also adopted as the version used in the classroom to do the urban planning project. All stages of work during the seminar were supported by ESRI. 


\section{First Steps}

The first steps to get acquainted with the GIS were smaller mapping tasks, which the students solved individually. They, for example, defined places of "well-being" for young people. As a first result the students then mapped their city quarter (München-Neuhausen) in regard to their needs (cafés, little shops, bakeries, clubs etc.). The map only contained cartographic point symbols. The final map for München-Neuhausen was eventually published in 2012 by BARNIKEL, PLÖTZ \& PINZEK.

In due course, more self-guided exercises were executed with the help of the manual (BREYER, JOACHIM, SCHOBER \& TSCHIRNER (2010). Attached to the manual is a CD with the software ArcGIS 9.3.1. All in all the time to introduce the software and become familiar with it did not exceed two months (two lessons each week). Some of the students rapidly became (much) more proficient with the software than their teachers and for the remainder of the seminar developed into GIS-experts helping not only their peers but also the teachers performing their own duties within the project.

The next step towards urban planning was to start with the real project. The group decided upon an approximately one square kilometre large area in the north of Munich. The area is located between two lakes and is uninhabited. At the moment it is used for agriculture and horticulture only. The location was convenient for the urban planning project, because most students know it and do not live far from it. The seminar visited the area during an excursion day and also visited the architectural department at the Ludwig-MaximiliansUniversity in Munich. Afterwards two architects were invited to the seminar and worked with the students for two weeks.

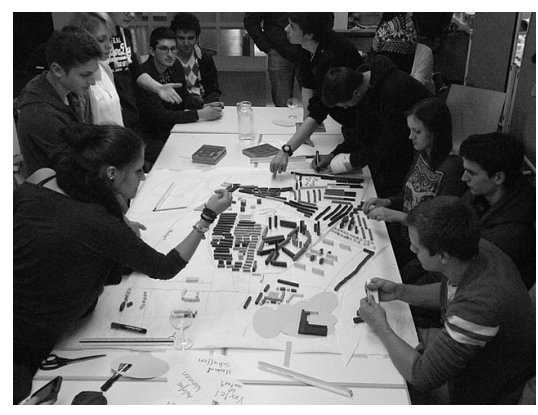

\section{Project Implementation}

\subsection{The analogue model}

Before beginning with the GIS-work, the students first had to build the quarter as an analogue model out of styrofoam blocks. The quarter was divided into twelve parts (twelve members of the seminar) and every student was allotted a certain number of a total of 10.000 inhabitants to care for as well as to include different buildings for the local infrastructure (schools, kindergardens, supermarkets, restaurants, public transportation etc.) into his or her part. The model size was approximately $3 \times 2$ metres in an unused classroom. 


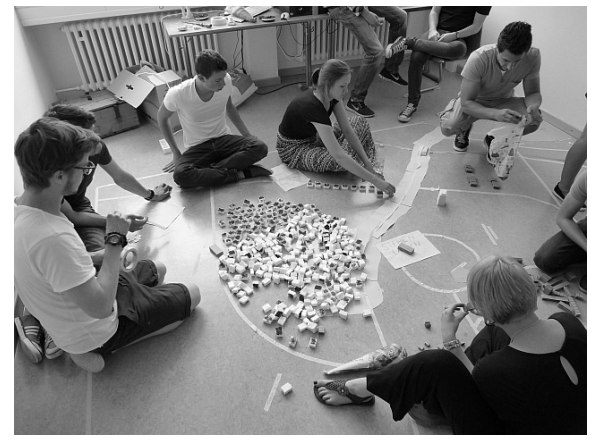

Fig. 2: Starting to build the analogue model in an unused classroom

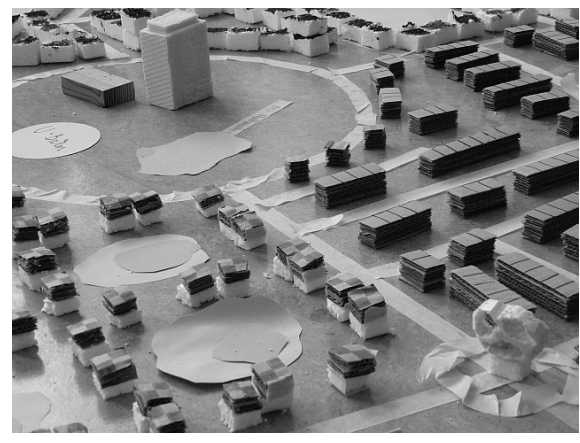

Fig. 3: The finished city quarter model just before starting the GIS work

\subsection{Main topic: Identity}

The quarter was to become distinctively "young". The main aim was to create an area where young people would love to live and where inhabitants from all over the world would feel at home at once, a necessary preoccupation since several members of the seminar and a lot of students in the school have a migration background. Important aspects were green areas and a river connecting the two lakes (a detail which was dropped later on), but also the idea of a local but at the same time international identity. One quickly adopted idea was to erect an oversize Bavarian lederhosen cast in bronze and an ultralarge pretzel to not only mirror the Bavarian background of the quarter but also to humorously play with traditional conceptions in order to make it easier for non-Bavarians to attach to "Plötzing".

\subsection{Working with ArcGIS}

Students nowadays in general are familiar with geoinformation, e.g. Google Maps etc. Our work with a GIS was meant to turn passive users into active ones, and to enlarge their understanding for the underlying processes of GI. Even though students are used to working with tabulation programmes and text editing in general, working with the complex structures of ArcGIS 9.3.1 took their knowledge about software to a new level. The ubiquitous trial-and-error technique rapidly delivered good results. Mistakes were erased quickly by group discussion and mutual support. Due to the fact that some of the students are planning to take on creative jobs after school, and that others want to try technical careers, a fruitful mixture within the group was achieved.

Just before finishing the project an unexpected problem came up. The houses had been designed as point-shape-files in ArcGIS instead of polygons, a relict from the early map of "well-being". Thus, zooming in and out was not possible, nobody had thought of that. But in a last effort the group managed to re-shape the map and to finalize it during some additional hours of work at home. Surprisingly enough the students were not contented with results that did not look "professional" and rather invested more time and energy to bring their project to a presentable end. 


\section{Results}

The project of urban planning was finished in time. During the process the seminar took part in two competitions and is going to take part in a third one in summer about municipal planning in Munich. This project is believed to be easily transferable to other cities/regions, where various communities provide online lay planning tools (also for schools). The use of ArcGIS can be highly recommended, the students quickly familiarised themselves with the necessities of urban planning, and the numerous restrictions that have to be kept in mind. Several students mentioned they would keep working with GIS in the future, even though they were unsure in what context.

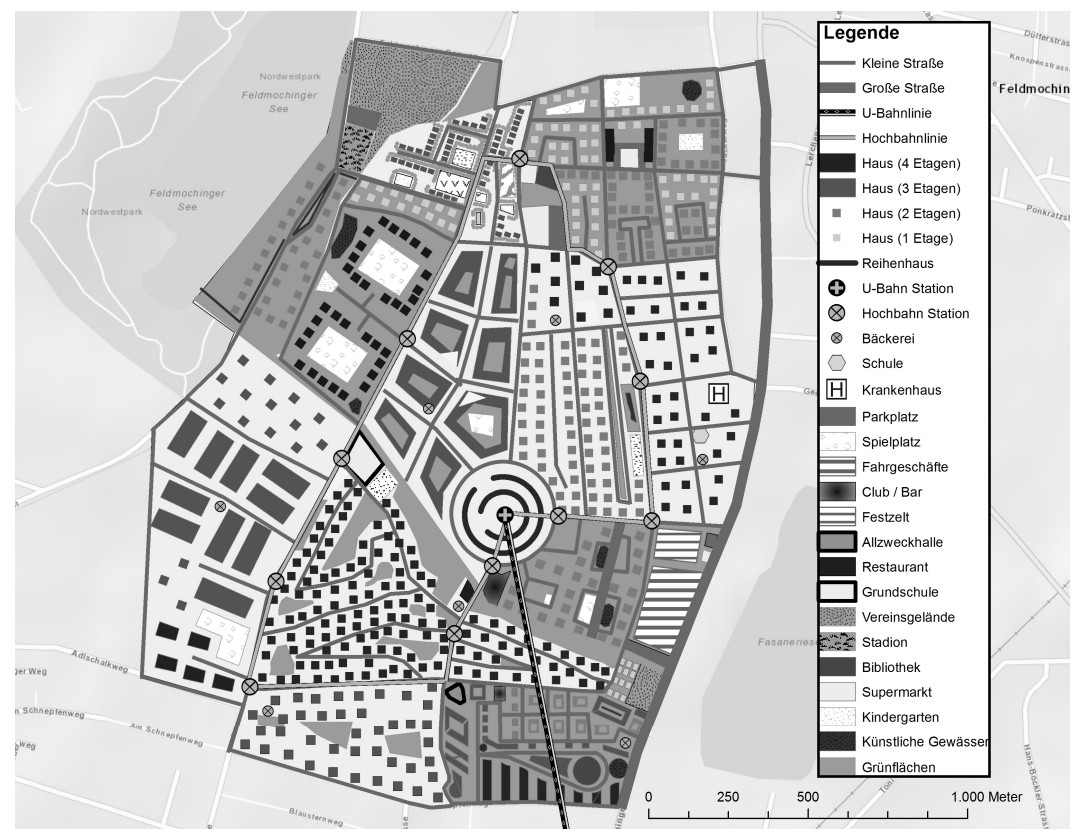

Fig. 4: The last version of "Plötzing" as it appears in ArcGIS. (Compilation: Tarek Nour-Eddine)

\section{References}

BARnikel, F., PlÖtZ, R. \& PINZEK, K. (2012), Ein Jugendstadtplan für München-Neuhausen. arcAktuell, 1/2012, 40.

Breyer, J., JoAchim, J., Schober, D. \& Tschirner, S. (2010), Haack Weltatlas - GISUnterricht mit Atlas und ArcGIS von ESRI. Stuttgart/Gotha, 159 p. 